\title{
Further evidence for the contribution of the BRCA1-interacting protein-terminal helicase 1 (BRIP1) gene in breast cancer susceptibility
}

\author{
L.P. Ren, Y.S. Xian, D.M. Diao, Y. Chen, Q. Guo and C.X. Dang \\ Department of Oncological Surgery, \\ First Hospital Affiliated to the Medical College of Xi' an Jiaotong University, \\ Xi'an, Shanxi, China \\ Corresponding author: C.X. Dang \\ E-mail: renleipengxs@126.com
}

Genet. Mol. Res. 12 (4): 5793-5801 (2013)

Received March 3, 2013

Accepted July 26, 2013

Published November 22, 2013

DOI http://dx.doi.org/10.4238/2013.November.22.6

ABSTRACT. BRCA1-interacting protein C-terminal helicase 1 (BRIP1) is a DNA helicase that influences the DNA repair ability and tumor suppressor function of BRCA1. Truncating BRIP1 mutations have been described as cancer susceptibility alleles. To evaluate BRIPI polymorphisms as risk factors for breast cancer, we performed a detailed analysis of possible single nucleotide polymorphisms (rs2048718, rs4988344, rs8077088, rs6504074, rs4986764, rs4986763, rs11079454, rs7213430, rs34289250, rs4988345, and rs12937080) using the MassARRAY system. A total of 319 patients with breast cancer and 306 healthy control females from the Chinese Han population enrolled in the study. A weak association was found between the rs4986764 allele (exon 18) and breast cancer. The frequency of the rs 4986764 $\mathrm{C}$ allele was significantly higher in breast cancer patients than in healthy controls $\left[\chi^{2}=4.089, \mathrm{P}=0.043\right.$, odds ratio $(\mathrm{OR})=0.781,95 \%$ confidence interval $(\mathrm{CI})=0.614-0.992]$. Additionally, our study is the first to identify a significant association between rs 7213430 and breast cancer. Compared to healthy controls, patients with breast cancer had a 
higher frequency of the rs7213430 A allele $\left(\chi^{2}=8.865, \mathrm{P}=0.003\right.$, OR $=0.700,95 \% \mathrm{CI}=0.553-0.886)$. Furthermore, linkage disequilibrium was observed in two blocks ( $\left.\mathrm{D}^{\prime}>0.9\right)$. While significantly more T-A-C haplotypes ( $\mathrm{P}=0.001$, block 1$)$ were found in breast cancer patients, the frequency of $\mathrm{T}-\mathrm{T}$ haplotypes $(\mathrm{P}=0.008$, block 2$)$ was significantly higher in healthy controls. The possible association among rs4986764, rs7213430, and breast cancer risk merits further validation in an independent case-control study.

Key words: BRCA1-interacting protein-terminal helicase 1; Breast cancer; Single nucleotide polymorphisms

\section{INTRODUCTION}

In the Chinese population, breast cancer has an incidence of 16.39 per 100,000 women and negatively affects the lives and health of those afflicted. It is estimated that monogenic traits account for approximately $5 \%$ of all breast cancer cases (Bradbury and Olopade, 2007). Germline breast cancer 1 (BRCA1) or BRCA2 mutations account for $20-40 \%$ of familial breast cancer cases, but for less than $5 \%$ of breast cancer cases overall (Wooster and Weber, 2003). Despite this, more than $50 \%$ of genetic predisposition to breast cancer remains unexplained (Nathanson et al., 2001; Meindl, 2002; Turnbull and Rahman, 2008). Interestingly, recent studies have suggested that polymorphisms in BRCA1-interacting protein C-terminal helicase 1 (BRIP1) may be associated with breast cancer incidence (Barroso et al., 2009).

BRIP1 is a DNA-dependent ATPase and DNA helicase that influences BRCA-mediated DNA damage repair, and helps to maintain genomic stability (Cantor et al., 2001; Peng et al., 2006). BRIP1 is required for homologous recombination-mediated double-strand break repair (Litman et al., 2005), the execution of the G2/M cell-cycle checkpoint (Yu et al., 2003), and for normal progression through the $\mathrm{S}$ phase by assisting in the resolution of stalled replication forks (Kumaraswamy and Shiekhattar, 2007). BRIP1 is located approximately $20 \mathrm{Mb}$ telomeric to $B R C A 1$ in a region that is frequently lost in ovarian tumors; additionally, previous studies have suggested that BRIP1 may function as a tumor suppressor (Godwin et al., 1994). BRIP1 mutation saffecting domain activity or messenger RNA (mRNA) expression have been identified in early onset breast cancer patients, suggesting that BRIP1 plays a role in breast cancer susceptibility (Cantor et al., 2001, 2004).

The human BRIP1 gene is located on chromosome 17q21. It is comprised of 19 introns and 20 exons and encodes a protein of 1249 amino acids. Germline mutations in BRIPI are associated with Fanconi anemia, a chromosome instability disorder characterized by developmental abnormalities, bone marrow failure, and predisposition to cancer (Levitus et al., 2005). Truncated variants of BRIP1 have been identified as low-penetrance breast cancer susceptibility alleles (Seal et al., 2006). Two BRIP1 missense mutations (P47A and M299I) were originally described in early onset familial breast cancer cases (Cantor et al., 2001), and the P47A mutation was later shown to disrupt the ATPase and helicase activities of the protein (Cantor et al., 2004). The C47G polymorphism (rs4988351) was associated with an increased risk effect in breast cancer patients (Garcia-Closas et al., 2006). These data suggest that BRIP1 is a good candidate for moderate/low penetrance genetic susceptibility to breast 
cancer. Previous studies have analyzed potential associations between BRIPl variants and breast cancer risk, either by mutation analysis or by genotyping, to select single nucleotide polymorphisms (SNPs) within the gene (Lei and Vorechovsky, 2003; Rutter et al., 2003; Sigurdson et al., 2004; Lewis et al., 2005; Garcia-Closas et al., 2006; Vahteristo et al., 2006). Although the rs2048718 (5'-untranslated region, UTR), rs4988345 (exon 15), and rs4986764 (exon 18) polymorphisms have been previously examined in the context of breast cancer, these genetic association studies have failed to produce consistent results (Luo et al., 2002; Lei and Vorechovsky, 2003; Song et al., 2007; Pabalan et al., 2013). Furthermore, several important SNPs, such as rs2048718, rs4986764, rs4986763, rs11079454, and rs7213430, have not been included in previous studies. Thus, additional study needs to be performed to determine whether these SNPs modulate the risk of disease on their own, or if they correlate with other causative SNPs, and if they are present in other populations.

The aim of this study was to evaluate whether common variants (rs2048718, rs4988344, rs8077088, rs6504074, rs4986764, rs4986763, rs11079454, rs7213430, rs34289250, rs4988345, and rs12937080) in BRIP1 are associated with breast cancer risk using an SNP tagging approach within an association study design.

\section{MATERIAL AND METHODS}

\section{Subjects}

A total of 319 cases of breast adenocarcinoma were included in the study. All cases were confirmed to be invasive breast cancer by histopathology. The mean age of patients was $50.5 \pm 6.6$ years. All patients received surgical treatment between February 2006 and June 2012 in the Department of Oncological Surgery of the First Hospital Affiliated to the Medical College of Xi' an Jiaotong University. Patients diagnosed with cervical or ovarian cancers were excluded. In total, 306 healthy blood donors (mean age of $52.1 \pm 7.8$ years) were recruited at the Medical Examination Center of the First Hospital Affiliated to the Medical College of Xi' an Jiaotong University. Participants were excluded if they participated in other studies or had a history of seizures, hematological diseases, or severe liver or kidney impairment. All participants were Han Chinese from the Shanxi Province, but were not genetically related. Written informed consent was obtained from all participants. The study protocol was approved by the Ethics Committee of the Medical College of Xi'an Jiaotong University.

\section{Selection of polymorphisms and genotyping}

To select potentially functional SNPs, we focused our attention on SNPs occurring within the promoter region, UTRs, and exons of BRIP1. Previous studies have shown significant associations between SNPs of BRIP1 and cancer diseases. A total of 11 SNPs located within BRIP1 were selected for genotyping. We used the Han Chinese population in Beijing and a minor allele frequency cut-off (MAF) $\geq 5 \%$ (HapMap Data Release 27). SNPs analyzed included rs2048718, located in the 5'-UTR, rs12937080, located in intron 4, rs4988344, located in intron 5, rs 8077088 and rs6504074, located in intron 6, rs34289250, located in intron 7 , rs4988345, located in exon 15 , rs4986764, located in exon 18, rs4986763, located in exon 20, and rs11079454 and rs7213430, which are both locatedin the 3'-UTR. 
Three to five milliliters peripheral blood was collected from each participant and placed in EDTA-containing specimen tubes. Genomic DNA was extracted using the EZNATM Blood DNA Midi Kit (Omega Bio-Tek, Norcross, GA, USA) according to manufacturer instructions; samples were then stored at $-20^{\circ} \mathrm{C}$ until use. Sequences for primers and probes, along with specific assay conditions used for each polymorphism, are detailed in Table S1. SNP genotyping was performed using the Mass ARRAY system (Sequenom, San Diego, CA, USA) and matrix-assisted laser desorption ionization-time of flight (MALDITOF) mass spectrometry. Resulting spectra were processed with the Typer Analyzer software (Sequenom), and genotype data were generated for all samples. The final genotype call rate of each SNP was greater than $90 \%$, and the total genotyping rate was $99.7 \%$, thus ensuring the liability of further statistical analysis.

\section{Statistical analysis}

Genotype frequency and Hardy-Weinberg equilibrium were evaluated with the chi square test for each individual polymorphism. Potential associations between breast cancer and each polymorphism were analyzed using the Fisher exact test or the Pearson chi square test. All statistical analyses were carried out using SPSS16.0. The odds ratios (ORs) and the $95 \%$ confidence intervals (CIs) were calculated to estimate the strength of association by unconditional logistic regression analysis. The $\mathrm{D}^{\prime}$ values for each pair of markers were calculated and visualized through the program Haploview v4.2 (Zaykin et al., 2002). Haplotype blocks were defined according to the criteria of Zhao (2004). These criteria were implemented in Haploview in order to examine if the SNPs identified as significant in the single-marker association analysis also existed in the haplotype blocks. Bonferroni's corrections were used in multiple tests, and the $\mathrm{P}$ value was divided by the total number of loci or haplotypes.

\section{RESULTS}

We genotyped 11 SNPs present within BRIP1 in 319 breast cancer cases and 306 controls. The genotype distribution of the three polymorphisms was consistent with HardyWeinberg equilibrium and is shown in Table 1. Analysis of strong linkage disequilibrium in patients with breast cancer relative to healthy controls revealed that three SNPs (rs11079454, rs7213430, and rs4986763) were located in haplotype block 1, and two SNPs (rs4986764 and rs8077088) were located in haplotype block 2 (D' > 0.9, Figure 1). The distribution of genotype, allele, and haplotype frequencies, along with all statistical analyses, in patients with breast cancer compared to healthy controls are listed in Tables 1 to 3 .

Compared to healthy controls, patients with breast cancer carried a higher frequency of the rs $4986764 \mathrm{C}$ allele $\left(\chi^{2}=4.089, \mathrm{P}=0.043\right.$, OR $\left.=0.781,95 \% \mathrm{CI}=0.614-0.992\right)$; however, it did not pass the threshold value cut-off $(\mathrm{P}=0.00625)$. We did find a significant association of the rs 7213430 allele with breast cancer. The frequency of the A allele was significantly higher in breast cancer patients than in healthy controls $\left(\chi^{2}=8.865, \mathrm{P}=0.003\right.$, $\mathrm{OR}=0.700,95 \% \mathrm{CI}=0.553-0.886)$. All differences remained statistically significant even after Bonferroni's corrections. 


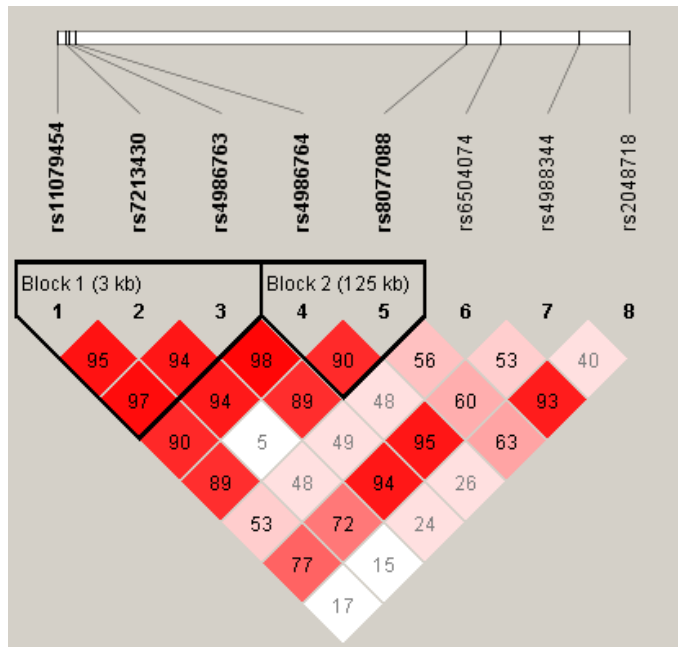

Figure 1. Linkage disequilibrium plot of the 11 SNPs in the BRIP1 gene. Values in squares are the pairwise calculation of $\mathrm{D}^{\prime}$.

\begin{tabular}{|c|c|c|c|c|c|c|c|c|c|c|c|}
\hline Variable & Location & MAF & & enotype (N, & & $\mathrm{P}^{\mathrm{a}}$ & $\chi^{2}, \mathrm{P}^{\mathrm{b}}$ & Allele ( & $(\mathrm{N}, \%)$ & $\chi^{2}, \mathrm{Pc}^{\mathrm{c}}$ & $\mathrm{OR}\left(95 \% \mathrm{Cl}^{d}\right)$ \\
\hline rs2048718 & 5'-UTR & 0.231 & TT & $\mathrm{TC}$ & $\mathrm{CC}$ & 0.288 & $4.053,0.132$ & $\mathrm{~T}$ & $\mathrm{C}$ & $0.396,0.529$ & 0.918 \\
\hline $\begin{array}{l}\text { Control }(\mathrm{N}=305) \\
\text { Case }(\mathrm{N}=319)\end{array}$ & & & $\begin{array}{l}177(58.0) \\
201(63.0)\end{array}$ & $\begin{array}{r}115(37.7) \\
98(30.7)\end{array}$ & $\begin{array}{l}13(4.3) \\
20(6.3)\end{array}$ & & & $\begin{array}{l}469(76.9) \\
500(78.4)\end{array}$ & $\begin{array}{l}141(23.1) \\
138(21.6)\end{array}$ & & $(0.703-1.198)$ \\
\hline rs4988344 & Intron 5 & 0.382 & $\mathrm{CC}$ & CG & GG & 0.674 & $4.404,0.111$ & $\mathrm{C}$ & G & $3.067,0.080$ & 0.817 \\
\hline $\begin{array}{l}\text { Control }(\mathrm{N}=306) \\
\text { Case }(\mathrm{N}=319)\end{array}$ & & & $\begin{array}{l}43(14.1) \\
65(20.4)\end{array}$ & $\begin{array}{l}148(48.4) \\
145(45.5)\end{array}$ & $\begin{array}{l}115(37.6) \\
109(34.2)\end{array}$ & & & $\begin{array}{l}234(38.2) \\
275(43.1)\end{array}$ & $\begin{array}{l}378(61.8) \\
363(56.9)\end{array}$ & & $(0.652-1.024)$ \\
\hline rs8077088 & Intron 6 & 0.201 & GG & GT & TT & 0.553 & $3.832,0.147$ & G & $\mathrm{T}$ & $1.149,0.284$ & 0.862 \\
\hline $\begin{array}{l}\text { Control }(\mathrm{N}=306) \\
\text { Case }(\mathrm{N}=319)\end{array}$ & & & $\begin{array}{l}15(4.9) \\
12(3.8)\end{array}$ & $\begin{array}{r}92(30.1) \\
119(37.3)\end{array}$ & $\begin{array}{l}199(65.0) \\
188(58.9)\end{array}$ & & & $\begin{array}{l}122(19.9) \\
143(22.4)\end{array}$ & $\begin{array}{l}490(80.1) \\
495(77.6)\end{array}$ & & $(0.657-1.131)$ \\
\hline rs6504074 & Intron 6 & 0.240 & GG & GT & TT & 0.882 & $2.892,0.235$ & G & $\mathrm{T}$ & $1.144,0.285$ & 0.865 \\
\hline $\begin{array}{l}\text { Control }(\mathrm{N}=304) \\
\text { Case }(\mathrm{N}=319)\end{array}$ & & & $\begin{array}{l}176(57.9) \\
203(63.6)\end{array}$ & $\begin{array}{r}110(36.2) \\
95(29.8)\end{array}$ & $\begin{array}{l}18(5.9) \\
21(6.6)\end{array}$ & & & $\begin{array}{l}462(76.0) \\
501(78.5)\end{array}$ & $\begin{array}{l}146(24.0) \\
137(21.5)\end{array}$ & & $(0.664-1.128)$ \\
\hline rs4986764 & Exon 18 & 0.338 & $\mathrm{CC}$ & CT & TT & 0.608 & $5.804,0.055$ & $\mathrm{C}$ & $\mathrm{T}$ & $4.089,0.043$ & 0.781 \\
\hline $\begin{array}{l}\text { Control }(\mathrm{N}=306) \\
\text { Case }(\mathrm{N}=319)\end{array}$ & & & $\begin{array}{l}132(43.1) \\
168(52.7)\end{array}$ & $\begin{array}{l}141(46.1) \\
120(37.6)\end{array}$ & $\begin{array}{l}33(10.8) \\
31(9.7)\end{array}$ & & & $\begin{array}{l}405(66.2) \\
456(71.5)\end{array}$ & $\begin{array}{l}207(33.8) \\
182(28.5)\end{array}$ & & $(0.614-0.992)$ \\
\hline rs4986763 & Exon 20 & 0329 & $\mathrm{CC}$ & $\mathrm{CT}$ & TT & 0.978 & $4.372,0.112$ & $\mathrm{C}$ & $\mathrm{T}$ & $1.868,0.172$ & 0.846 \\
\hline $\begin{array}{l}\text { Control }(\mathrm{N}=304) \\
\text { Case }(\mathrm{N}=319)\end{array}$ & & & $\begin{array}{l}137(45.1) \\
168(52.7)\end{array}$ & $\begin{array}{l}134(44.1) \\
115(36.1)\end{array}$ & $\begin{array}{l}33(10.9) \\
36(11.3)\end{array}$ & & & $\begin{array}{l}408(67.1) \\
451(70.7)\end{array}$ & $\begin{array}{l}200(32.9) \\
187(29.3)\end{array}$ & & $(0.665-1.075)$ \\
\hline rs11079454 & 3'UTR & 0.472 & TT & TA & AA & 0.275 & $2.329,0.312$ & $\mathrm{~T}$ & A & $0.721,0.396$ & 0.908 \\
\hline $\begin{array}{l}\text { Control }(\mathrm{N}=306) \\
\text { Case }(\mathrm{N}=319)\end{array}$ & & & $\begin{array}{l}90(29.4) \\
94(29.5)\end{array}$ & $\begin{array}{l}143(46.7) \\
164(51.4)\end{array}$ & $\begin{array}{l}73(23,9) \\
61(19.1)\end{array}$ & & & $\begin{array}{l}323(52.8) \\
352(55.2)\end{array}$ & $\begin{array}{l}289(47,2) \\
286(44.8)\end{array}$ & & $(0.727-1.134)$ \\
\hline rs 7213430 & 3'UTR & 0.379 & $\mathrm{AA}$ & $\mathrm{AG}$ & GG & 0.143 & $8.396,0.015$ & $\mathrm{~A}$ & G & $8.865,0.003$ & 0.700 \\
\hline $\begin{array}{l}\text { Control }(\mathrm{N}=306) \\
\text { Case }(\mathrm{N}=319)\end{array}$ & & & $\begin{array}{l}124(38.9) \\
165(51.7)\end{array}$ & $\begin{array}{l}132(43.1) \\
117(36.7)\end{array}$ & $\begin{array}{l}50(16.3) \\
37(11.6)\end{array}$ & & & $\begin{array}{l}380(62.1) \\
447(70.1)\end{array}$ & $\begin{array}{l}232(37.9) \\
191(29.9)\end{array}$ & & $(0.553-0.886)$ \\
\hline
\end{tabular}

a values for Hardy-Weinberg equilibrium in controls. ${ }^{\mathrm{b}} \mathrm{P}$ values for genotype frequency dirrerence. ${ }^{\mathrm{c}} \mathrm{P}$ values for allele frequency dirrerence. ${ }^{\mathrm{d}} \mathrm{P}$ values for allele frequency dirrerence. $\mathrm{MAF}=$ minor allele frequency. Alpha value is adjusted by Bonferroni's correction and statistically significant results $(\mathrm{P}<0.00625)$. 
Table 2. BRIP1 haplotype in block 1 frequencies and the results of their associations with risk of breast cancer.

\begin{tabular}{|c|c|c|c|c|c|}
\hline \multirow[t]{2}{*}{ Haplotype $^{\mathrm{a}}$} & \multirow[t]{2}{*}{ Cases (N, \%) } & \multirow[t]{2}{*}{ Controls (N, \%) } & \multicolumn{3}{|c|}{ Statistics } \\
\hline & & & $\chi^{2}$ & $\mathrm{P}^{\mathrm{b}}$ & OR $(95 \% \mathrm{CI})$ \\
\hline$A-A-C$ & $143(44.8)$ & $141(46.1)$ & 0.099 & 0.754 & $0.951(0.694-1.303)$ \\
\hline$T-G-T$ & 94 (29.5) & $98(32.0)$ & 0.481 & 0.488 & $0.887(0.631-1.246)$ \\
\hline$T-A-C$ & $81(25.4)$ & $46(15.0)$ & 10.352 & 0.001 & $1.924(1.286-2.876)$ \\
\hline
\end{tabular}

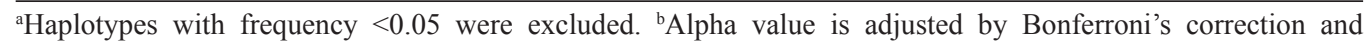
statistically significant results $(\mathrm{P}<0.0167)$.

Table 3. BRIP1 haplotype in block 2 frequencies and the results of their associations with risk of breast cancer.

\begin{tabular}{|c|c|c|c|c|c|}
\hline \multirow[t]{2}{*}{ Haplotype $^{a}$} & \multirow[t]{2}{*}{ Cases (N, \%) } & \multirow[t]{2}{*}{ Controls (N, \%) } & \multicolumn{3}{|c|}{ Statistics } \\
\hline & & & $\chi^{2}$ & $\mathrm{P}^{\mathrm{b}}$ & OR $(95 \% \mathrm{CI})$ \\
\hline $\begin{array}{l}\mathrm{C}-\mathrm{T} \\
\mathrm{T}-\mathrm{T}\end{array}$ & $\begin{array}{r}171(53.6) \\
76(23.8)\end{array}$ & $\begin{array}{l}143(46.7) \\
102(33.3)\end{array}$ & $\begin{array}{l}2.951 \\
6.933\end{array}$ & $\begin{array}{l}0.086 \\
0.008\end{array}$ & $\begin{array}{l}1.317(0.962-1.804) \\
0.626(0.441-0.888)\end{array}$ \\
\hline
\end{tabular}

${ }^{\mathrm{a}}$ Haplotypes with frequency $<0.05$ were excluded. ${ }^{\mathrm{b}}$ Alpha value is adjusted by Bonferroni's correction and statistically significant results $(\mathrm{P}<0.025)$.

Additionally, we performed association analysis to determine if haplotype (blocks 1 and 2) was associated with increased risk of developing breast cancer. Interestingly, a significantly higher number of T-A-C haplotypes (block $1: \chi^{2}=10.352, \mathrm{P}=0.001, \mathrm{OR}=1.924$, $95 \% \mathrm{CI}=1.286-2.876)$ were found in breast cancer patients compared to healthy individuals. In contrast, the frequency of T-T haplotypes (block $2: \chi^{2}=6.933, \mathrm{P}=0.008, \mathrm{OR}=0.626$, $95 \% \mathrm{CI}=0.441-0.888$ ) was significantly higher in the healthy controls. These differences remained statistically significant after Bonferroni's corrections.

\section{DISCUSSION}

Aberrant DNA helicase activity negatively affects DNA repair and genomic stability, thus increasing the likelihood of cancer development. Germline BRIP1 mutations are associated with breast cancer and Fanconi anemia (Cantor et al., 2001; Litman et al., 2005). Thus, common variants in the BRIP1 gene are candidates for breast cancer susceptibility. We used an SNP tagging approach to evaluate the association between common variants in BRIP1 and the risk of developing breast cancer. Here, we provide additional evidence for the contribution of $B R I P 1$ polymorphisms to breast cancer susceptibility.

BRIP1 rs4986764 is a missense mutation $(\mathrm{T} \rightarrow \mathrm{C}$; Ser $\rightarrow$ Pro) in exon 18 , and has been frequently reported (Pabalan et al., 2013). The C (Ser) allele variant in Pro919Ser has been associated with an increased risk of breast cancer in a kin-cohort study (Sigurdson et al., 2004). While some evidence suggests that there is an association between the BRIP1 rs4986764 polymorphism and breast cancer (Seal et al., 2006), other studies have failed to reach the same conclusion (Vahteristo et al., 2006; Huo et al., 2009). Results from the present study support only a weak association between rs4986764 and breast cancer. The frequency of the rs $4986764 \mathrm{C}$ allele was significantly higher in breast cancer patients than in healthy control individuals. However, it did not pass the threshold value $(\mathrm{P}=0.00625)$. Results using both an SNP tagging approach and a case-control study (Vahteristo et al., 2006) 
found no association between this polymorphism and breast cancer (Song et al., 2007). While recent meta-analysis data suggest that the rs4986764 polymorphism is not a breast cancer predisposition allele, any association with low risk disease cannot be discounted (Pabalan et al., 2013). Based on these observations, our data indicate that the difference in rs4986764 C allele frequencies is nothighly significant. On its own, BRIP1 likely only has a modest influence on breast cancer risk.

SNPs present within the 3'-UTR of genes can modify miRNA binding sites resulting in altered mRNA expression (Nana-Sinkam and Croce, 2011). Such a scenario has been described for BRIP1. SNPs in the 3'-UTR of BRIP1 have been shown to influence mRNA stability and regulate gene expression (Jiang et al., 2013). As a result, these SNPs may affect genetic susceptibility to breast cancer. To the best of our knowledge, our study is the first to describe a significant association between the rs 7213430 allele and breast cancer. The frequency of the A allele was significantly higher in breast cancer patients than in healthy controls. Our study design enabled $97 \%$ power to detect an allele with this frequency with a type I error rate of 0.0001 , even if the true relative risk was 1.3. Despite this strong result, the association between the BRIP1 rs7213430 allele and genetic susceptibility to breast cancer needs further investigation.

Previous studies have indicated that the rare BRIP1 variant rs4988345 (Arg173Cys) impairs protein translocation to the nucleus and may also modify breast cancer susceptibility (Lei and Vorechovsky, 2003; Song et al., 2007). Since the MAF for this variant is very low $(0.0065)$ in the Chinese Han population, we had limited power to confirm or refute this association using the case-control population of the current study. Song et al. (2007) reported that the MAF of rs4988344 was associated with increased risk of ovarian cancer, but not breast cancer. These associations were only borderline significant, and should be interpreted with caution. We did not find any association between this allele and genetic susceptibility to breast cancer in our study.

We performed additional analyses examining the interaction among polymorphisms and the observed strong linkage disequilibrium. Haplotype analysis revealed that significantly more T-A-C haplotypes (block 1) were found in patients with breast cancer. These results indicate that individuals with this haplotype of the BRIP1 gene are more susceptible to developing breast cancer. In contrast, significantly higher frequencies of T-T haplotypes were detected in healthy controls compared to breast cancer patients, suggesting that this haplotype may have a protective effect against breast cancer. This finding further supports a role of BRIP1 polymorphisms in breast cancer.

In conclusion, these findings warrant additional efforts aimed at identifying functional polymorphisms within, and close to, the BRIP1 gene. Such analyses should use a systemic approach and a larger sample set. The results of our study, in conjunction with future research, may help elucidate the biological mechanisms governing breast cancer, which may allow us to devise better treatment strategies.

\section{ACKNOWLEDGMENTS}

Research partially supported by the National Science Foundation of China.

\section{Supplementary material}




\section{REFERENCES}

Barroso E, Pita G, Arias JI, Menendez P, et al. (2009). The Fanconi anemia family of genes and its correlation with breast cancer susceptibility and breast cancer features. Breast Cancer Res. Treat. 118: 655-660.

Bradbury AR and Olopade OI (2007). Genetic susceptibility to breast cancer. Rev. Endocr. Metab. Disord. 8: 255-267.

Cantor S, Drapkin R, Zhang F, Lin Y, et al. (2004). The BRCA1-associated protein BACH1 is a DNA helicase targeted by clinically relevant inactivating mutations. Proc. Natl. Acad. Sci. U. S. A. 101: 2357-2362.

Cantor SB, Bell DW, Ganesan S, Kass EM, et al. (2001). BACH1, a novel helicase-like protein, interacts directly with BRCA1 and contributes to its DNA repair function. Cell 105: 149-160.

Garcia-Closas M, Egan KM, Newcomb PA, Brinton LA, et al. (2006). Polymorphisms in DNA double-strand break repair genes and risk of breast cancer: two population-based studies in USA and Poland, and meta-analyses. Hum. Genet. 119: 376-388.

Godwin AK, Vanderveer L, Schultz DC, Lynch HT, et al. (1994). A common region of deletion on chromosome 17q in both sporadic and familial epithelial ovarian tumors distal to BRCA1. Am. J. Hum. Genet. 55: 666-677.

Huo X, Lu C, Huang X, Hu Z, et al. (2009). Polymorphisms in BRCA1, BRCA1-interacting genes and susceptibility of breast cancer in Chinese women. J. Cancer Res. Clin. Oncol. 135: 1569-1575.

Jiang Y, Qin Z, Hu Z, Guan X, et al. (2013). Genetic variation in a hsa-let-7 binding site in RAD52 is associated with breast cancer susceptibility. Carcinogenesis 34: 689-693.

Kumaraswamy E and Shiekhattar R (2007). Activation of BRCA1/BRCA2-associated helicase BACH1 is required for timely progression through S phase. Mol. Cell Biol. 27: 6733-6741.

Lei $\mathrm{H}$ and Vorechovsky I (2003). BACH1 $517 \mathrm{C} \rightarrow \mathrm{T}$ transition impairs protein translocation to nucleus: a role in breast cancer susceptibility? Int. J. Cancer 104: 389-391.

Levitus M, Waisfisz Q, Godthelp BC, de Vries Y, et al. (2005). The DNA helicase BRIP1 is defective in Fanconi anemia complementation group J. Nat. Genet. 37: 934-935.

Lewis AG, Flanagan J, Marsh A, Pupo GM, et al. (2005). Mutation analysis of FANCD2, BRIP1/BACH1, LMO4 and SFN in familial breast cancer. Breast Cancer Res. 7: R1005-R1016.

Litman R, Peng M, Jin Z, Zhang F, et al. (2005). BACH1 is critical for homologous recombination and appears to be the Fanconi anemia gene product FANCJ. Cancer Cell 8: 255-265.

Luo L, Lei H, Du Q, von Wachenfeldt A, et al. (2002). No mutations in the BACH1 gene in BRCA1 and BRCA2 negative breast-cancer families linked to 17q22. Int. J. Cancer 98: 638-639.

Meindl A (2002). Comprehensive analysis of 989 patients with breast or ovarian cancer provides BRCA1 and BRCA2 mutation profiles and frequencies for the German population. Int. J. Cancer 97: 472-480.

Nana-Sinkam SP and Croce CM (2011). MicroRNAs as therapeutic targets in cancer. Transl. Res. 157: 216-225.

Nathanson KL, Wooster R and Weber BL (2001). Breast cancer genetics: what we know and what we need. Nat. Med. 7: 552-556.

Pabalan N, Jarjanazi H and Ozcelik H (2013). Association between BRIP1 (BACH1) polymorphisms and breast cancer risk: a meta-analysis. Breast Cancer Res. Treat. 137: 553-558.

Peng M, Litman R, Jin Z, Fong G, et al. (2006). BACH1 is a DNA repair protein supporting BRCA1 damage response. Oncogene 25: 2245-2253.

Rutter JL, Smith AM, Davila MR, Sigurdson AJ, et al. (2003). Mutational analysis of the BRCA1-interacting genes ZNF350/ZBRK1 and BRIP1/BACH1 among BRCA1 and BRCA2-negative probands from breast-ovarian cancer families and among early-onset breast cancer cases and reference individuals. Hum. Mutat. 22: 121-128.

Seal S, Thompson D, Renwick A, Elliott A, et al. (2006). Truncating mutations in the Fanconi anemia J gene BRIP1 are low-penetrance breast cancer susceptibility alleles. Nat. Genet. 38: 1239-1241.

Sigurdson AJ, Hauptmann M, Chatterjee N, Alexander BH, et al. (2004). Kin-cohort estimates for familial breast cancer risk in relation to variants in DNA base excision repair, BRCA1 interacting and growth factor genes. BMC Cancer 4: 9.

Song H, Ramus SJ, Kjaer SK, Hogdall E, et al. (2007). Tagging single nucleotide polymorphisms in the BRIPI gene and susceptibility to breast and ovarian cancer. PLoS One 2: e268.

Turnbull C and Rahman N (2008). Genetic predisposition to breast cancer: past, present, and future. Annu. Rev. Genomics Hum. Genet. 9: 321-345.

Vahteristo P, Yliannala K, Tamminen A, Eerola H, et al. (2006). BACH1 Ser919Pro variant and breast cancer risk. BMC Cancer 6: 19.

Wooster R and Weber BL (2003). Breast and ovarian cancer. N Engl. J. Med. 348: 2339-2347.

Yu X, Chini CC, He M, Mer G, et al. (2003). The BRCT domain is a phospho-protein binding domain. Science 302: 639-642. 
Zaykin DV, Westfall PH, Young SS, Karnoub MA, et al. (2002). Testing association of statistically inferred haplotypes with discrete and continuous traits in samples of unrelated individuals. Hum. Hered. 53: 79-91.

Zhao JH (2004). 2LD, GENECOUNTING and HAP: Computer programs for linkage disequilibrium analysis. Bioinformatics 20: 1325-1326. 